\title{
Metástasis vaginal de carcinoma de células renales
}

\author{
Osório L, Sabell F, Soares J, Lima E, Marcelo F. \\ Servicio de Urología, Hospital General Santo Antonio, Porto. Portugal.
}

Actas Urol Esp. 2008;32(6):653-655

\begin{abstract}
RESUMEN
METÁSTASIS VAGINAL DE CARCINOMA DE CÉLULAS RENALES

Las metástasis vaginales del carcinoma de células renales (CCR) han sido descritas en raras ocasiones. Describimos un caso de CCR metastizado, en una paciente de sexo femenino de 75 años que debutó con un cuadro de hematuria macroscópica y malestar vaginal. El estudio reveló la presencia de un tumor renal asociado a una masa vaginal. La paciente fue sometida a nefrectomía radical y escisión de la lesión vaginal, siendo diagnosticado un CCR metastizado. Este caso revela la variabilidad en la presentación del CCR. El carcinoma de células claras vaginal es una entidad rara, por lo que todas estas lesiones deben ser consideradas como potencialmente secundarias a una afectación renal.

Palabras clave: Carcinoma de células renales. Metástasis. Vaginal.

\section{ABSTRACT}

VAGINAL METASTASIS FROM RENAL CELL CARCINOMA

Vaginal metastases in renal cell carcinoma (RCC) have been reported in rare situations. We present a case of metastatic RCC in a 75-year-old woman, initially presenting with haematuria and vaginal pain. Workup further revealed a renal tumor and a vaginal mass. A nephrectomy and local vaginal excision were performed, leading to the diagnosis of metastatic RCC.

This case illustrate the variability in RCC presentation. Also, because vaginal clear cell carcinoma is rare, all such lesions should be considered potentially renal in origin.

Keywords: Renal cell carcinoma. Metastases. Vaginal.
\end{abstract}

$\mathrm{E}$ carcinoma de células renales (CCR) es uno de los tumores urológicos más agresivos, representando cerca del 3\% de las neoplasias del adulto. Este tumor está caracterizado por una evolución clínica imprevisible. Aproximadamente el $30 \%$ de los pacientes con CCR, muestra enfermedad metastásica en su forma de presentación inicial y, el 40\% restante desarrollaran metástasis durante el seguimiento. Menos del 5\% de los pacientes presentan una metástasis solitaria en el momento del diagnóstico ${ }^{1}$.

Las neoplasias vaginales representan aproximadamente el 1-2\% de las neoplasias del tracto genital. La metastatización vaginal a pesar de ser poco común, es más frecuente que los tumores primarios. Con excepción de los casos raros de enfermedad metastásica con origen en los órganos extra-genitales, la vagina es vulgarmente un lugar de metastatización de los tumores genito-urinarios, especialmente del cuello de útero, endometrio y riñón. La metástasis vaginal como forma de presentación de la enfermedad es extremadamente rara.

\section{CASO CLÍNICO}

Paciente de sexo femenino, 75 anos, con hematuria macroscópica con 1 mes de evolución, asociada a lesión nodular de la pared anterior de la vagina (Fig. 1). Realizado TAC abdominal, reveló neoformación renal izquierda con $6 \mathrm{~cm}$ de diámetro (Fig. 2). La paciente fue sometida a nefrectomía radical con biopsia de la lesión vaginal. El estudio anatomopatológico reveló un carcinoma de células renales (grado 4 Fuhrman)-T3aNOM1 en el riñón y una metástasis de cáncer de células renales en la lesión vaginal (Fig. 3). Posteriormente la paciente mantuvo perdidas hemáticas vaginales severas con necesidad de soporte transfusional, siendo sometida a metastatectomía (Fig. 4). Falleció 1 mes después del diagnóstico inicial, de caquexia, presentando en ese momento metastatización ósea generalizada. 


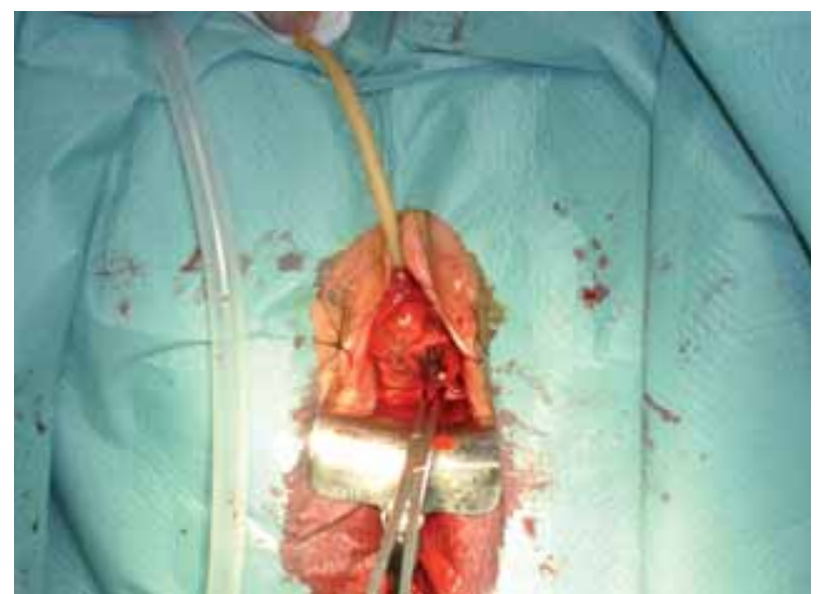

FIGURA 1

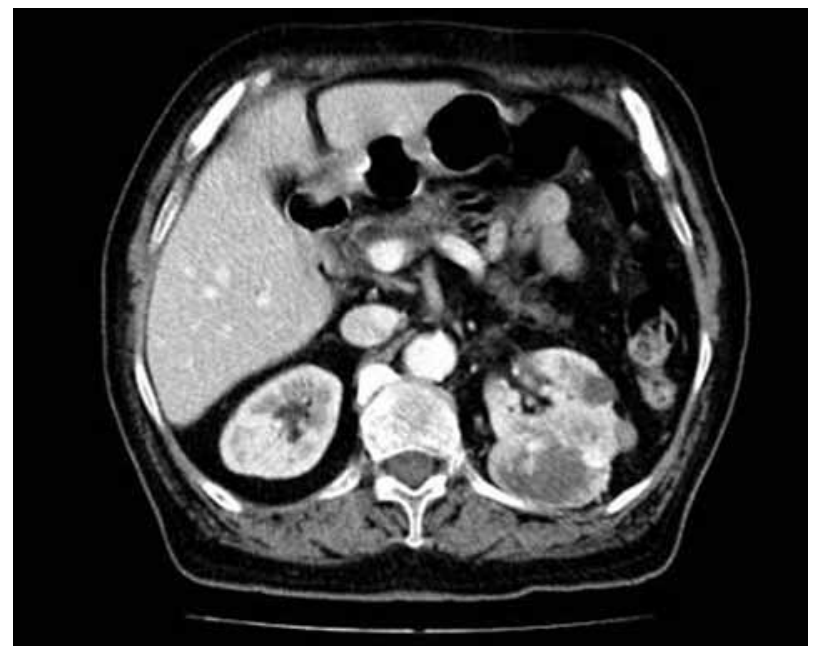

FIGURA 2

\section{DISCUSION}

El CCR puede surgir sobre varias formas de presentación, incluyendo una variedad de síndromes paraneoplásicos. La triada clásica de hematuria, dolor lumbar y masa palpable ocurre apenas en el 5$15 \%$ de los casos, correlacionándose vulgarmente con enfermedad avanzada, siendo actualmente designada como "tríada tardía". La sintomatología de la enfermedad metastásica puede ser la queja inicial en más del $30 \%$ de los pacientes. Actualmente la mayoría de los tumores renales forman parte de hallazgos incidentales debido al uso generalizado de la ecografía y de la tomografía computarizada.

$\mathrm{El}$ adenocarcinoma de la vagina representa el 5\% de las neoplasias vaginales ${ }^{2}$, siendo el $91 \%$ de ellas metastásicos. Como tal, el adenocarcinoma de la vagina debe ser considerado como una lesión metastásica hasta que no se demuestre lo contrario ${ }^{3}$ El
CCR se caracteriza por una presentación clínica y un comportamiento biológico imprevisible, siendo su forma de diseminación aún oscura.

La aparición de la lesión vaginal vulgarmente precede y, raramente surge posteriormente al diagnóstico de tumor renal. En uno de los estudios publicados, los síntomas de presentación en el 65\% de los pacientes con CCR con metástasis vaginales fueron secreción vaginal, hemorragia o el efecto masa ${ }^{2}$. En el 61\% de los casos, la localización primaria del tumor fue el riñón izquierdo. Normalmente las metástasis surgen en el mismo lado que el tumor renal primario.

El flujo retrógrado de contraste de la vena renal izquierda a la vena ovárica izquierda, plexos ovári$\cos$ y uterovaginales $\mathrm{y}$, consecuentemente para la vena ovárica derecha fue demostrado angiograficamente ${ }^{4}$. Pueden existir anastomosis entre el plexo uterovaginal y la vena obturadora, que a su vez recibe ramos tributarios de las venas genitales externas, explicando la presencia de metástasis localizadas en la parte más distal de la vagina ${ }^{5}$. Así, la forma más probable de diseminación parece ser la diseminación venosa retrógrada ${ }^{4}$. La predilección del tumor primario a localizarse en el riñón izquierdo favorece esta hipótesis.

Aproximadamente el $2 \%$ de los pacientes con CCR presentan una metástasis solitaria, en la mayoría de las situaciones pulmonar. Una vez que la supervivencia de estos pacientes pueda aumentarse, la metastasectomía en el momento de la nefrectomía podrá ser una opción razonable. La nefrectomía radical ante la presencia de enfermedad metastásica podrá ser considerada también como forma de control de los síntomas severos, incluyendo el dolor lumbar intratable, la hemorragia, la fiebre y la hipercalcemia secundaria a la producción

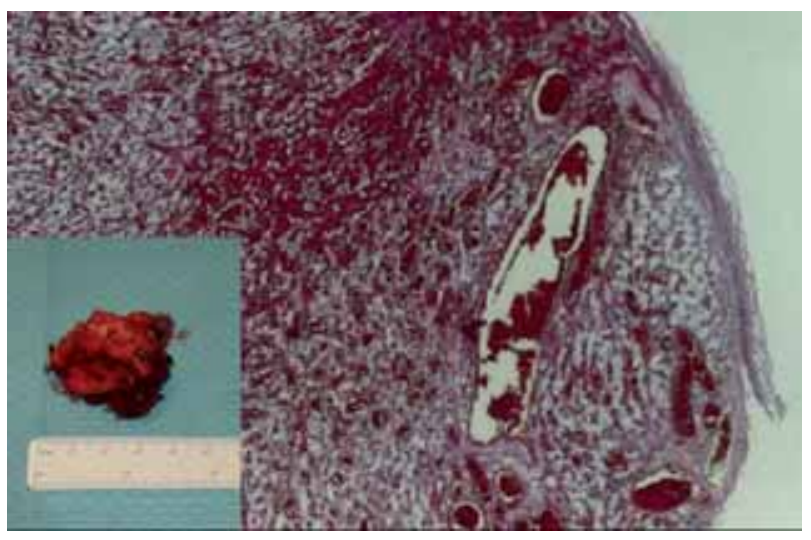

FIGURA 3 


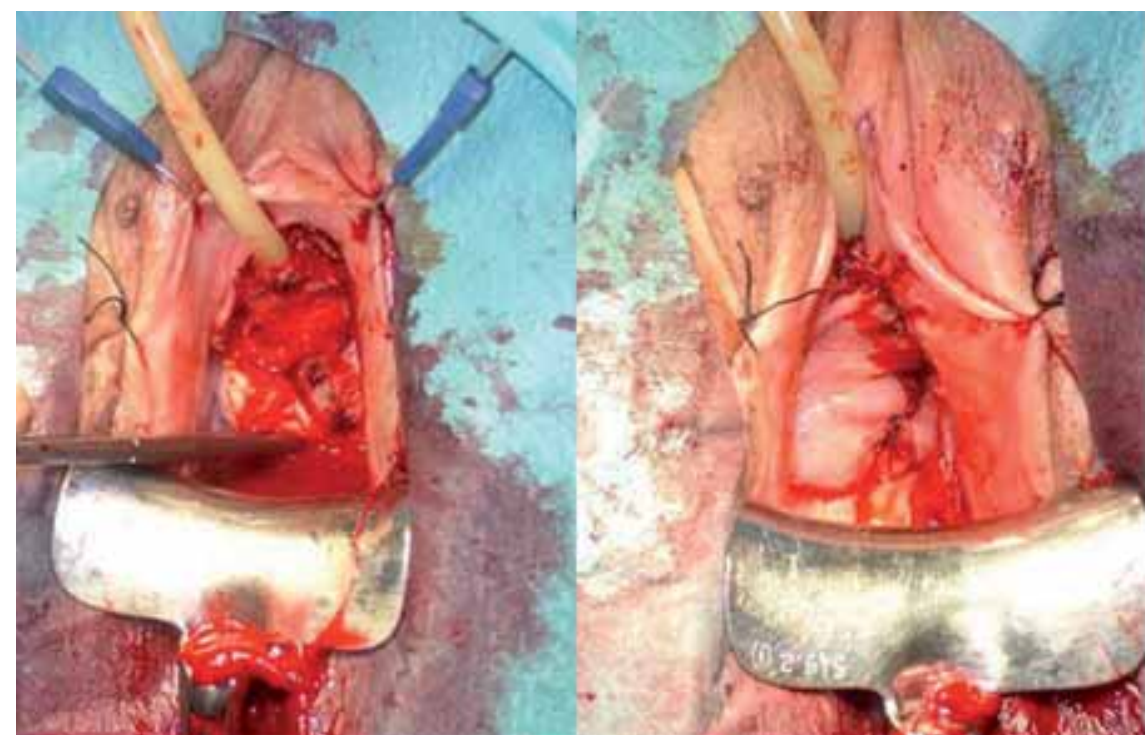

FIGURA 5

hormonal por el tumor. La nefrectomía en presencia de enfermedad metastásica podrá también ser una opción razonable en los pacientes que deseen participar en protocolos experimentales. Resultados preliminares sugieren que una terapia cito-reductora para el CCR metastatizado, podrá mejorar la respuesta a la inmunoterapia. Los pacientes que desarrollan una metástasis solitaria después de la remoción del tumor primario, presentan una supervivencia mayor que aquellos que exhiben una metástasis solitaria en la presencia de neoplasia renal. Según O'Dea et $\mathrm{al}^{6}$, entre los pacientes nefrectomizados que posteriormente desarrollaron metástasis que fueron resecadas, la supervivencia a los 5 años fue superior al $23 \% \mathrm{y}$, varios pacientes exhibieron supervivencias mayores. En los estudios de Middleton y Tolia $^{7,8}$, los pacientes sometidos a nefrectomía y remoción de la metástasis presentaban una tasa de supervivencia superior al 35\% a los 5 años.

Frecuentemente, el pronóstico fue más favorable en pacientes en que la metastasectomia fue realizada en lesiones secundarias localizadas en el pulmón, glándula suprarrenal o en el cerebro.

El factor pronóstico más importante en los pacientes con metástasis vaginales de CCR es la presencia o ausencia de metastatización secundaria en otros órganos ${ }^{2}$. La presencia de metástasis múltiples, recurrencia metastásica y afectación de la vena renal ejercen efectos adversos en la supervivencia $^{9}$.
Queiroz et $\mathrm{al}^{10}$ describen un caso de metástasis vaginal de carcinoma de células renales diagnosticado por citología cervicovaginal; a pesar de ello, no existen estudios concluyentes en la literatura que favorezcan el uso de la citología en el diagnóstico o seguimiento de estas pacientes.

La metastatización vaginal por el CCR es rara, a pesar de ello, podrá ser la primera evidencia de la existencia de un tumor primario. Cuando el examen citológico vaginal revela la presencia de un adenocarcinoma de células claras, la metastatización por un CCR deberá ser considerado como diagnóstico diferencial. Debe prestarse atención cuando un adenocarcinoma de células claras es encontrado, especialmente en una mujer posmenopáusica.

La excisión local y/o la radioterapia son las terapias aconsejadas para las metástasis vaginales aisladas en pacientes previamente sometidas a nefrectomía radical.

\section{REFERENCIAS}

1. Wahner-Roedler DL, Sebo TJ.: Renal cell carcinoma: diagnosis based on metastatic manifestations. Mayo Clin Proc 1997;72 (10):935-941.

2. Tarraza HM Jr, Meltzer SE, DeCain M, Jones MA.: Vaginal metastases from renal cell carcinoma : report of four cases and review of the literature. Eur J Gynaecol Oncol 1998;19(1):14-18.

3. Allard JE, McBroom JW, Zahn CM, McLeod D, Maxwell GL. Vaginal metastasis and thrombocytopenia from renal cell carcinoma. Gynecol Oncol 2004; 92(3):970-973.

4. Mulcahy JJ, Furlow WL. Vaginal metastasis from renal cell carcinoma: radiographic evidence of possible route of spread. J Urol 1970;104(1):50-52.

5. Abraham R, Thomas DR, Foster MC. Vaginal bleeding as a presentation of metastatic renal cell carcinoma. BJU Int 1999; 84(3):384-385.

6. O'dea MJ, Zincke H, Utz DC, Bernatz PE. The treatment of renal cell carcinoma with solitary metastasis. J Urol 1978; 120(5):540-542.

7. Middleton RG. Surgery for metastatic renal cell carcinoma. J Urol 1967;97 (6):973-977.

8. Tolia BM, Whitmore WF Jr.: Solitary metastasis from renal cell carcinoma. J Urol 1975;114(6):836-838.

9. McNichols DW, Segura JW, DeWeerd JH.: Renal cell carcinoma: long term survival and late recurrence. JUrol 1981;126(1):17-23.

10. Queiroz C, Bacchi CE, Oliveira C, Carvalho M, Santos DR.: Cytologic diagnosis of vaginal metastasis from renal cell carcinoma. A case report. Acta Cytol 1999;43(6):1098-1100.

Correspondencia autor: Dr. L. Osorio

Hospital Geral Santo António Largo Professor Abel Salazar, 4099-001 Porto (Portugal). Teléfono: 00351938468754

E-mail autor: lposorio@gmail.com

Información del artículo: Nota Clínica

Trabajo recibido: noviembre 2007

Trabajo aceptado: diciembre 2007 